\title{
Antibody-based enzyme-linked immunosorbent assay for determination of anti-PGL-I specific circulating immune complex in leprosy patients
}

\author{
J. TOMIMORI-YAMASHITA*, P. CRUAUD**, \\ O. ROTTA*, \& P. H. LAGRANGE*** \\ * Department of Dermatology, Federal University of São Paulo, \\ Brazil \\ ** Service de Microbiologie, Hôpital Jean Verdier, Bondy, France \\ *** Service de Microbiologie, Hôpital Saint Louis, Paris, France
}

\section{Accepted for publication 5 April 1999}

\begin{abstract}
Summary A serological study was performed in 122 individuals: 75 leprosy patients and 47 healthy controls. The ELISA test was performed for IgG and IgM using the glycolipid PGL-I antigen from Mycobacterium leprae. Circulating immune complexes (CIC) were isolated by PEG 6000 precipitation method and after dissociation with an acid solution, the IgG and IgM specific against PGL-I were tested with the ELISA test. The multibacillary patients had high levels of antibodies, compared with paucibacillary patients and controls. The antibodies isolated from the CIC presented a similar spectrum spectral distribution as the serology. A positive correlation between the levels of free and CIC bound antibodies was observed. In contrast with tuberculosis patients, specific antibodies present in CIC were not responsible for false-negative results found in some multibacillary patients' serology, since no or very low levels of specific antibodies were found in PEG precipitated serum of these patients. No relation was observed with specific antibody levels detected in CIC during leprosy reactions.
\end{abstract}

\section{Introduction}

When the body establishes contact with a foreign substance, an immune response may occur. Two types of specific response can be observed: the cell-mediated and the humoral immune responses. Mycobacteria can stimulate antibody production directed specifically against mycobacterial antigens. A specific antigen PGL-I (phenolic glycolipid I) from Mycobacterium leprae has been described by Brennan and Barrow, ${ }^{1}$ and has been used for serodiagnosis

Part of this study has been presented at the 57th Meeting-The Society for Investigative Dermatology and European Society for Dermatological Research (May 1996, Washington)

Correspondence to: Dr Jane Tomimori-Yamashita, Department of Derrnatology, Federal University of São Paulo, Rua Botucatu 740, CEP 04023-900, São Paulo/SP, Brazil. Telefax: +55(11)571-2947. E-mail: jane.derrn@ originet.com.br. 
in leprosy. High levels of immunoglobulin G and M (IgG and IgM) against PGL-I have been detected in multibacillary patients, and some authors reported higher IgM than $\operatorname{IgG}^{2-4}$

However, a small proportion of multibacillary patients (BL and LL) have low levels of anti-PGL-I antibodies, as do most paucibacillary (BT and TT) patients. In tuberculosis, some authors recently found that the negativity of serological tests in patients with confirmed tuberculosis was due to specific immune complexes in the serum. ${ }^{5-8}$ We postulated that specific antibodies present within circulating immune complexes (CIC) would not be detected by the enzyme-linked immunosorbent assay (ELISA) test for PGL-I, and this could explain the false-negative reactions found in some paucibacillary and multibacillary patients sera before and during treatment.

Elevated CIC levels have been reported in leprosy patients ${ }^{9,10}$ and deposition or in situ formation is thought to be a precipitating factor for the development of the erythema nodosum leprosum (ENL). ${ }^{11}$ It is argued that some CIC are not eliminated and persist in the circulation, causing a hypersensitivity reaction, resulting in immune complexe (IC) disease, especially when they are deposited in blood vessel walls and peripheral tissues causing inflammation. ${ }^{12}$ The polyethylene glycol (PEG) precipitation test for CIC was performed to show the presence of specific anti-PGL-I antibody in the precipitates, and to verify if there is any relationship between the specific CIC levels and the presence of leprosy reaction (reversal reaction or erythema nodosum leprosum), as the real role of the specific CIC in the leprosy reaction is not certain.

\section{Materials and methods}

SERA

Seventy-five sera from patients with leprosy [13 lepromatous lepromatous (LL), 26 borderline lepromatous (BL), 3 borderline boderline (BB), 16 borderline tuberculoid (BT), 14 tuberculoid tuberculoid (TT) and 3 indeterminate] were obtained from the Department of Dermatology, UNIFESP-Escola Paulista de Medicina, São Paulo, Brazil. Their ages ranged from 14 to 63 years, and 39 female and 36 male patients were included. The diagnosis was made by clinical, bacteriological (slit skin smears), histopathological and immunological (Mitsuda reaction) features. The cases were classified according to the Ridley-Jopling classification. ${ }^{13}$ Operational classification of leprosy (World Health Organization, 1988) patients according to their type of treatment was gathered: LL and BL patients as multibacillary leprosy and BT and TT as paucibacillary leprosy. This classification was used in this report because the humoral response seems to corroborate such operational view. All sera were collected from patients before treatment, except from five who were treated for less than 1 year. Thirteen patients had type 1 reaction (reversal) and four patients type 2 reaction (ENL). Two to four samples of serial sera were collected from seven patients with leprosy reaction $(n=19$ sera). The interval between each collected sample was 15 days; these patients have been treated with prednisolone and/or thalidomide. In addition, sera from 47 normal blood donors from the same hospital in São Paulo, Brazil were included as controls. Their ages ranged from 18 to 57 years; 16 females and 31 males.

\section{ANTIGEN}

The natural PGL-I of Mycobacterium leprae was used. The methods for isolation, purification and characterization were reported previously. ${ }^{1}$ 
An enzyme-linked immunosorbent assay (ELISA) was performed, using the method described by Cruaud et al. ${ }^{14}$ for glycolipid mycobacterial antigens. Polystyrene microtitre plates purchased from COSTAR (USA) were coated with PGL-I (250 ng/well). For coating, the indicated amounts of antigen in $25 \mu$ of $n$-hexane were placed in the wells, and the solutions were left to dry overnight at $37^{\circ} \mathrm{C}$. To ascertain the absence of nonspecific adsorption, one well treated with $25 \mu \mathrm{l}$ of $n$-hexane without antigen was included for each test. The storage of sera were at $-20^{\circ} \mathrm{C}$, until the serology was performed. The sera were diluted $1 / 250$ in PBS (phosphate buffer saline) containing $0.5 \%$ of porcine gelatin (Sigma, USA). After saturation by PBS containing $0.5 \%$ of porcine gelatin (overnight at $4^{\circ} \mathrm{C}$ ), the plates were washed with PBS without Tween (Micro plate washer LP 35, Diagnostics Pasteur, France) and $100 \mu \mathrm{l}$ of diluted sera was incubated at $37^{\circ} \mathrm{C}$ during 90 or $180 \mathrm{~min}$ for IgG or IgM determination, respectively. After washings, the conjugates with appropriate dilution were allowed to react for $2 \mathrm{~h}$ at $37^{\circ} \mathrm{C}$; the conjugates were goat antihuman IgM (anti $\mu$ )/beta-galactosidase (Biosys, France). After washing, the appropriate substrate, 2-nitrophenyl-beta-D-galactopyranoside (Merck, Germany) was added, and the plates were incubated at $37^{\circ} \mathrm{C}$ for $30 \mathrm{~min}$. To correlate the data, three known tested sera having low, medium and high levels of antibodies were used as standards. They were included in each plate, and PBS was used as the control (zero point activity). The color developed was read at $405 \mathrm{~nm}$, using an automatic spectrophotometer (LP 400, SanofiDiagnostics Pasteur, France). After reading, for each plate, a curve was drawn using the zero and standard values after calculation of the slope and the correlation coefficient (cc). If these data were not satisfactory (slope too low, cc below 98\%...), the plate was rejected and the assay was repeated. The values of tested sera were corrected as follows: first, the difference between absorbance of serum and the nonspecific absorption was calculated. Then, the data were calculated to establish the corrected $\Delta 405$ values by using the curve of the standards.

\section{PEG PRECIPITATION}

The PEG 6000 (polyethylene glycol 6000, Prolabo, Paris, France) precipitation test for CIC (circulating immune complexes) precipitation was performed according to the method described previously by Louzir et al., ${ }^{15}$ developed from the original technique by Ohlson and Zetterstrand. ${ }^{16}$ The sera were diluted 1/1 with PBS (pH 7.4) without Tween. To $200 \mu$ l of diluted serum, $200 \mu \mathrm{l}$ of $5 \%$ PEG 6000 in $150 \mathrm{mM} \mathrm{NaCl}, 20 \mathrm{mM}$ potassium phosphate buffer $(\mathrm{pH} 7 \cdot 4)$ was added. The mixture was incubated overnight at $4^{\circ} \mathrm{C}$. The precipitates were collected by centrifugation $\left(1550 \mathrm{~g}, 20 \mathrm{~min}, 4^{\circ} \mathrm{C}\right)(\mathrm{CR} 4.11$, Jouan, France), washed twice with $2.5 \%$ PEG 6000 in buffer described below and then were dissolved in $100 \mu \mathrm{l}$ of $150 \mathrm{mM}$ $\mathrm{NaCl}, 20 \mathrm{mM}$ potassium phosphate buffer $(\mathrm{pH} 7 \cdot 5) 10 \mathrm{mM}$ ethylene diamine tetraacetic acid [EDTA (Sigma, France)] by incubation for $30 \mathrm{~min}$ at $37^{\circ} \mathrm{C}$. To $100 \mu \mathrm{l}$ of the solubilized CIC solution, $50 \mu \mathrm{l}$ of cold $0 \cdot 2 \mathrm{M} \mathrm{HCl}$-glycine $(\mathrm{pH} 2 \cdot 8)$ was added and incubated at $4^{\circ} \mathrm{C}$ for $15 \mathrm{~min}$. This solution was neutralized with $25 \mu \mathrm{l}$ of $1 \mathrm{M} \mathrm{K}_{2} \mathrm{HPO}_{4}(\mathrm{pH} \mathrm{9 \cdot 0)}$ and then diluted $1 / 20$ by adding $1825 \mu$ l of PBS containing $0.5 \%$ of porcine gelatin without Tween. This solution was tested for ELISA within 30 minutes. The main difference between the CIC precipitation test and the current ELISA serology was the dilution factor for CIC 1/20, and for the sera, $1 / 250$. 
SUPERNATANT ANALYSIS

After the overnight serum incubation at $4{ }^{\circ} \mathrm{C}$ with $2.5 \%$ PEG solution and first centrifugation, $40 \mu \mathrm{l}$ of the supernatant (corresponding volume of $10 \mu \mathrm{l}$ of serum) were diluted in $2.5 \mathrm{ml}$ of PBS with $0.5 \%$ of porcine gelatin, and distributed in the ELISA plates. The final dilution corresponded to an equivalent $1 / 250$ serum dilution. For some sera $(n=24)$, a double PEG precipitation was performed. The first supernatants were re-precipitated, repeating the same technique for PEG precipitation. The precipitate was analysed to verify if some CIC remained in the supernatant after this first PEG precipitation. The second supernatant obtained from the re-precipitation was tested for ELISA in following proceeding: $160 \mu \mathrm{l}$ of the second supernatant was diluted in $2.34 \mathrm{ml}$ PBS containing $0.5 \%$ porcine gelatin (a final serum dilution of $1 / 250$ ), and tested for ELISA. It allowed us to determine whether the antibody activity remained after two PEG precipitations.

\section{STATISTICAL ANALYSIS}

The ANOVA (Analysis of Variance) and Kruskal-Wallis non-parametric test were performed for statistical analysis of the antibodies levels in respect to the different forms of leprosy and the control group. A box plot graphic was developed to represent the 10, 25, 50 (median), 75 and 90 percentiles of serology repartition results of each leprosy forms and control group, analyzing the IgG and IgM anti-PGL-I levels. The scattergraphs were used to represent the correlation of antibodies levels in leprosy patients and for all these statistical analysis the correlation coefficient was calculated. The contingency tables were analysed by the $\chi^{2}$ test, using a significant $P$-value of $<5 \%$.

\section{Results}

INDIVIDUALS AND MEAN ANTIBODY LEVELS AGAINST PGL-I IN SERUM

The initial assessment was performed by ELISA, using PGL-I as antigen, on all whole serum before PEG precipitation. As expected, higher IgG and IgM antibodies levels were observed (Figure 1) in the serum of LL and BB leprosy patients as compared with those of BT and TT patients. A significant difference $(P<0.05)$ in IgG and IgM levels was found between healthy controls and multibacillary (LL $+\mathrm{BL}$ ) patients. Mean levels were also significantly higher $(P<0.05)$ in multibacillary $(\mathrm{LL}+\mathrm{BL})$ patients than in paucibacillary patients $(\mathrm{BT}+\mathrm{TT})$. The corrected $\Delta 405$ optical density value corresponding to the 95 percentiles of all healthy subjects was taken as the normal upper limit for each immunoglobulin class (Table 1). Using this definition, we obtained a specificity of $95 \%$ for IgG and IgM classes. The sensitivity was $74.0 \%$ and $57 \cdot 1 \%$ for IgG and IgM classes, respectively for the leprosy patients considered as a whole group. However, when the leprosy group was subclassified into two groups, the multibacillary and the paucibacillary, the sensitivity was $97.4 \%$ and $92.3 \%$ for $\operatorname{IgG}$ and $\operatorname{IgM}$ classes in the multibacillary group and $45.2 \%$ and $19 \cdot 3 \%$ for IgG and IgM classes for the paucibacillary group. LL and BL leprosy patients were significantly $(P<0.001)$ more positive than BT and TT patients for both immunoglobulin classes. The presence of specific IgG and IgM antibody against PGL-I in dissociated CIC was tested in the same sera after the PEG precipitation. 


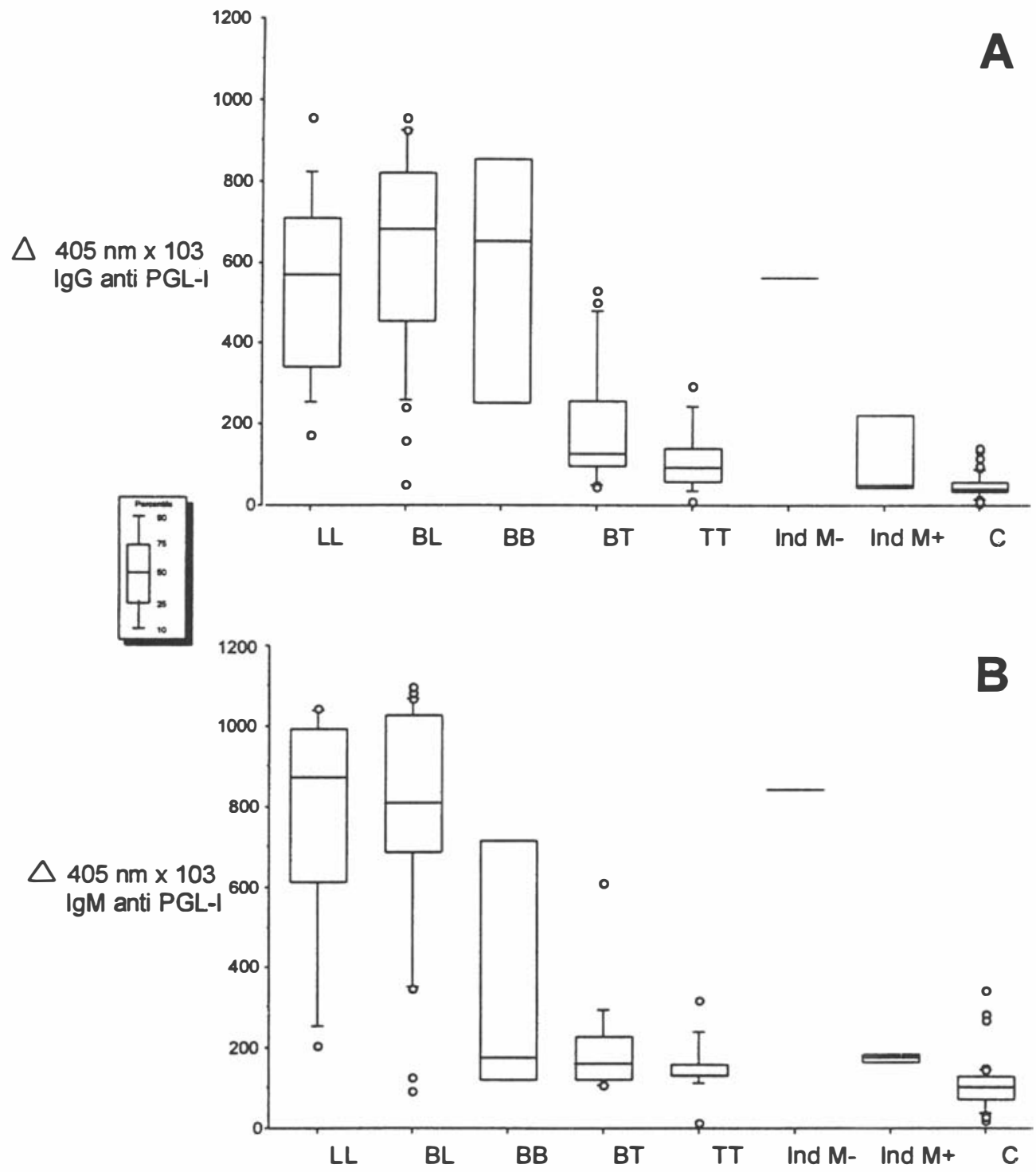

Figure 1. Distribution of antibodies levels anti-PGL-I IgG (A) and IgM (B) in whole sera according to the different forms of leprosy: 13 lepromatous lepromatous (LL), 26 borderline lepromatous (BL), 3 borderline borderline (BB), 16 borderline tuberculoid (BT), 14 tuberculoid tuberculoid (TT), one indeterminate with negative Mitsuda's reaction (Ind $\mathrm{M}-$ ), 2 indeterminate with positive Mitsuda's reaction (Ind M+) patients and 47 healthy controls (C).

\section{DEMONSTRATION OF SPECIFIC ANTIBODY AGAINST PGL-I IN IMMUNE COMPLEXES}

All collected sera were subjected to PEG precipitation, the CIC were dissociated and the liberated IgG and IgM immunoglobulin classes were assayed by ELISA using the PGL-I antigen. Figure 2 illustrates the distribution of the individual IgG and IgM antibody levels after PEG precipitation in respect to the different forms of leprosy and control group. As 
Table 1. Repartition of positive results for each group of leprosy patients. The cut-off point is defined as the corrected $\Delta 405$ optical density value corresponding to the 95 percentiles of all healthy subjects is taken as the normal upper limit in each immunoglobulin class. Using this definition, the specificity is $95 \%$

\begin{tabular}{|c|c|c|c|c|c|c|c|c|c|}
\hline \multirow[b]{2}{*}{ Groups } & \multicolumn{3}{|c|}{$\begin{array}{c}\text { Free } \\
\text { immunoglobulins }\end{array}$} & \multicolumn{3}{|c|}{$\begin{array}{l}\text { CIC complexed } \\
\text { immunoglobulins }\end{array}$} & \multicolumn{3}{|c|}{$\begin{array}{l}\text { Both free and CIC complexed } \\
\text { Immunoglobulins }\end{array}$} \\
\hline & $\begin{array}{c}\mathrm{IgG} \\
\text { pos. }(\%)\end{array}$ & $\begin{array}{c}\operatorname{IgM} \\
\text { pos. }(\%)\end{array}$ & $\begin{array}{c}\text { Both } \\
\text { pos. }(\%)\end{array}$ & $\begin{array}{c}\text { IgG } \\
\text { pos. }(\%)\end{array}$ & $\begin{array}{c}\text { IgM } \\
\text { pos. }(\%)\end{array}$ & $\begin{array}{c}\text { Both } \\
\text { pos. }(\%)\end{array}$ & $\begin{array}{c}\text { IgG } \\
\text { pos. }(\%)\end{array}$ & $\begin{array}{c}\text { IgM } \\
\text { pos. }(\%)\end{array}$ & $\begin{array}{c}\text { Both } \\
\text { pos. }(\%)\end{array}$ \\
\hline $\mathrm{LL}(n=13)$ & $13(100)$ & $12(92 \cdot 3)$ & $13(100)$ & $11(84 \cdot 6)$ & $10(76 \cdot 9)$ & $11(84 \cdot 6)$ & $13(100)$ & $12(92 \cdot 3)$ & $13(100)$ \\
\hline $\mathrm{BL}(n=26)$ & $25(96 \cdot 2)$ & $24(92 \cdot 3)$ & $26(96 \cdot 2)$ & $20(74 \cdot 0)$ & $23(85 \cdot 2)$ & $23(85 \cdot 2)$ & $26(96 \cdot 3)$ & $25(92 \cdot 6)$ & $26(96 \cdot 3)$ \\
\hline $\mathrm{BB}(n=3)$ & $3(100)$ & $1(33 \cdot 3)$ & $3(100)$ & $2(66 \cdot 7)$ & $1(33 \cdot 3)$ & $2(66 \cdot 7)$ & $3(100)$ & $1(33 \cdot 3)$ & $3(100)$ \\
\hline $\mathrm{BT}(n=16)$ & $8(50 \cdot 0)$ & $4(25 \cdot 0)$ & $8(50 \cdot 0)$ & $2(12 \cdot 5)$ & $2(12 \cdot 5)$ & $4(25 \cdot 0)$ & $10(62 \cdot 5)$ & $6(37 \cdot 5)$ & $10(62 \cdot 5)$ \\
\hline TT $(n=14)$ & $6(42.9)$ & $2(13 \cdot 3)$ & $6(40 \cdot 0)$ & $2(13 \cdot 3)$ & $2(13 \cdot 3)$ & $2(13 \cdot 3)$ & $6(40 \cdot 0)$ & $3(20 \cdot 0)$ & $6(40 \cdot 0)$ \\
\hline Ind. Mit $+(n=2)$ & $1(50 \cdot 0)$ & $0(0)$ & $1(33 \cdot 3)$ & $0(0)$ & $1(33 \cdot 3)$ & $1(33 \cdot 3)$ & $1(33 \cdot 3)$ & $1(33 \cdot 3)$ & $2(66 \cdot 7)$ \\
\hline Ind. Mit $-(n=1)$ & $1(100)$ & $1(100)$ & $1(100)$ & $0(0)$ & $1(100)$ & $1(100)$ & $1(100)$ & $1(100)$ & $1(100)$ \\
\hline
\end{tabular}

already shown in Figure 1, higher IgG and IgM antibody levels were observed in CIC of $\mathrm{BL}+\mathrm{LL}$ forms as compared with BT, TT and controls. The spectral distributions appeared to be similar, when the antibody titers were compared with those obtained with the whole serum before CIC precipitation. The difference between the BL + LL and the BT + TT form was more evident for IgM.

\section{RELATION BETWEEN ANTI-PGL-I FREE IMMUNOGLOBULINS AND SPECIFIC ANTIBODIES CONTAINED IN CIC}

As shown in Figure 3, individual sera with high titers of free IgM antibodies also had high titers of the same antibody isolated from CIC. Although the dilution was not the same for serology and CIC precipitation, a positive correlation was observed in patients between the free antibodies and those isolated from CIC $(r=0.885 ; P<0.01)$. Comparing leprosy patients with and without reaction, no significant difference on IgM isolated from CIC was noticed.

\section{SUPERNATANT ANALYSIS}

The analysis of the remained individual supernatants tested by the same ELISA method showed similar results in comparison with serology $(r=0.983, P<0 \cdot 01)$. No difference of free immunoglobulins levels was observed before and after PEG precipitation on the studied sera (Figure 4) indicating that free immunoglobulins were not coprecipitated by PEG. When the supernatant was re-precipitated by PEG, using the same technique, the precipitate obtained had very low or no antibody activity. The second supernatant had almost the same activity when compared with the first supernatant or serology (data not shown).

OCCURRENCE OF CIC AND FREE ANTIBODIES IN TYPE 1 AND TYPE 2 REACTIONS

A difference between patients with or without reaction (type 1 and 2) in relation to the specific antibodies levels, was not observed in all tested sera. The same analysis was also 


\section{$\triangle 405 \mathrm{~nm} \times 10^{3}$} IgG anti PGL-I

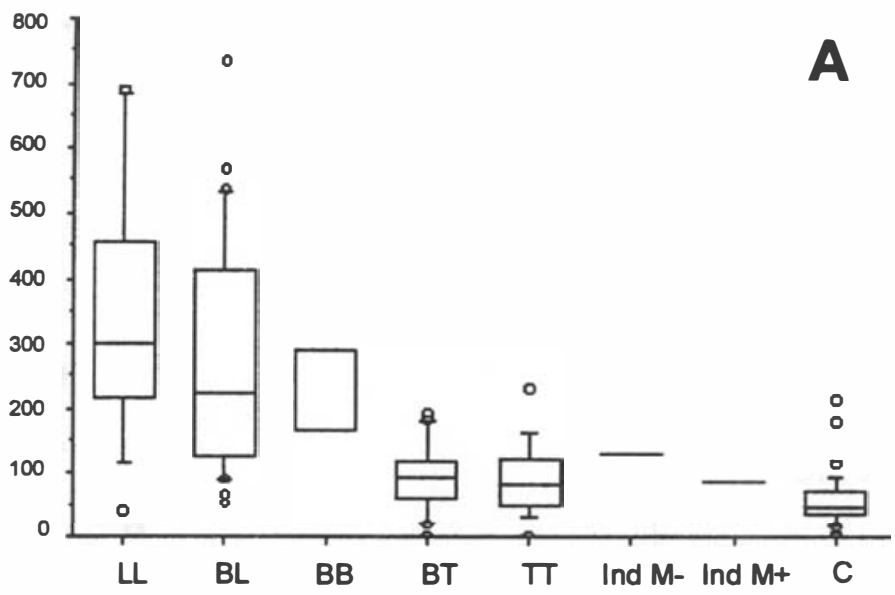

$\triangle 405 \mathrm{~nm} \times 10^{3}$ IgM anti PGL-I
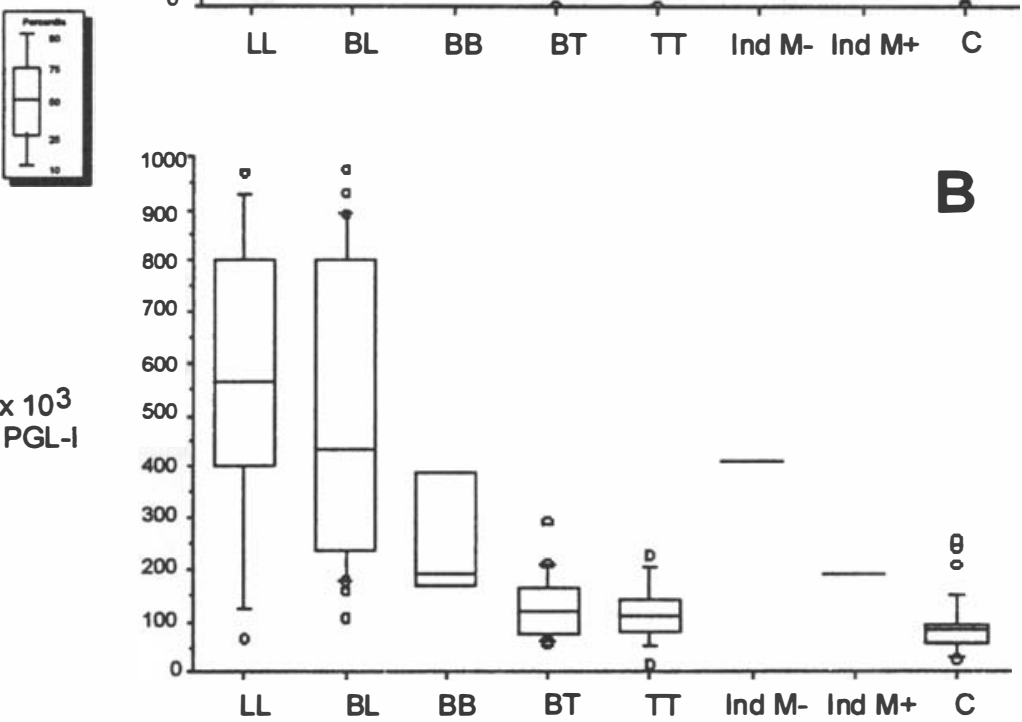

Figure 2. Distribution of dissociated anti-PGL-I IgG (A) and IgM (B) from polyethylene glycol 6000 precipitated circulating immune complexes according to the different forms of leprosy: 13 lepromatous lepromatous (LL), 26 borderline lepromatous (BL), 3 borderline borderline (BB), 16 borderline tuberculoid (BT), 14 tuberculoid tuberculoid (TT), one indeterminate with negative Mitsuda's reaction (Ind $M-$ ), 2 indeterminate with positive Mitsuda's reaction (ind $\mathrm{M}+$ ) patients and 47 healthy controls (C).

valid for antibodies isolated from CIC. No significant difference $\left(\chi^{2}=0 \cdot 171, P>0 \cdot 05\right)$ was observed comparing patients with or without leprosy reactions for anti-PGL-I antibodies isolated from CIC (Table 2). The cut-off-point for this analysis was $0 \cdot 253(\Delta 405)$ (mean value plus three standard deviations of obtained titres in the control group). Using this analysis separately for reaction type 1 and 2, we found the same results. There are no significant differences in patients with reaction type $1\left(\chi^{2}=0.263, P>0.05\right)$ or in patients with reaction type $2\left(\chi^{2}=0 \cdot 107, P>0 \cdot 05\right)$, compared to patients without leprosy reaction, although the number of patients with leprosy reaction was small.

Nine patients with BT form had reaction type 1 and among them, eight patients had negative IgM titres of anti-PGL-I isolated from CIC. Four patients with BL form had reaction type 2 , and 3 of them had positive titres for IgM anti-PGL-I isolated from CIC. 


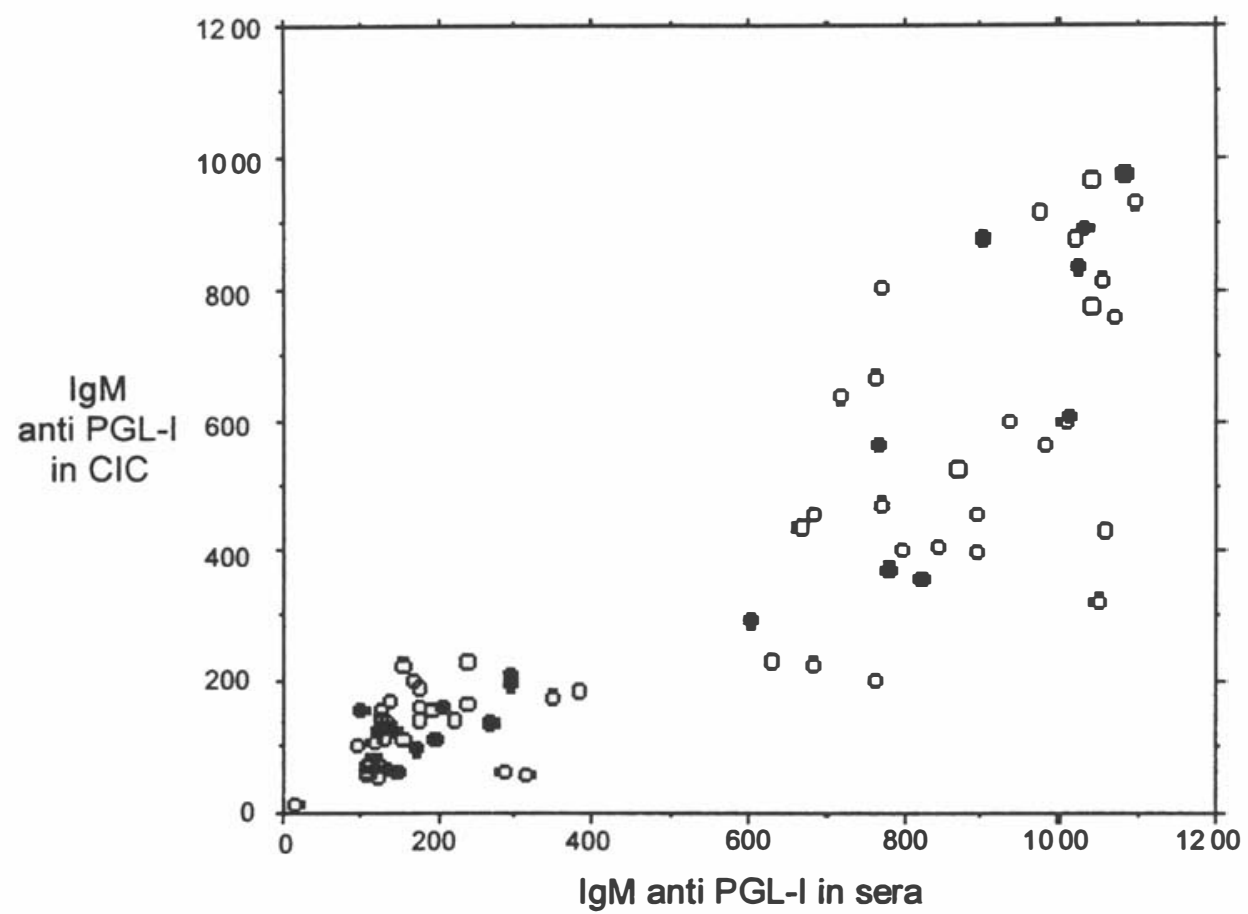

Figure 3. Scattergraphs showing individual paired IgM levels against PGL-I obtained by ELISA $\left(\Delta 405 \mathrm{~nm} \times 10^{3}\right)$ in sera and circulating immune complexes of leprosy patients. Open circles for patients without reaction and closed circles for patients with reactions $(r=0 \cdot 885, P \leq 0 \cdot 01)$.

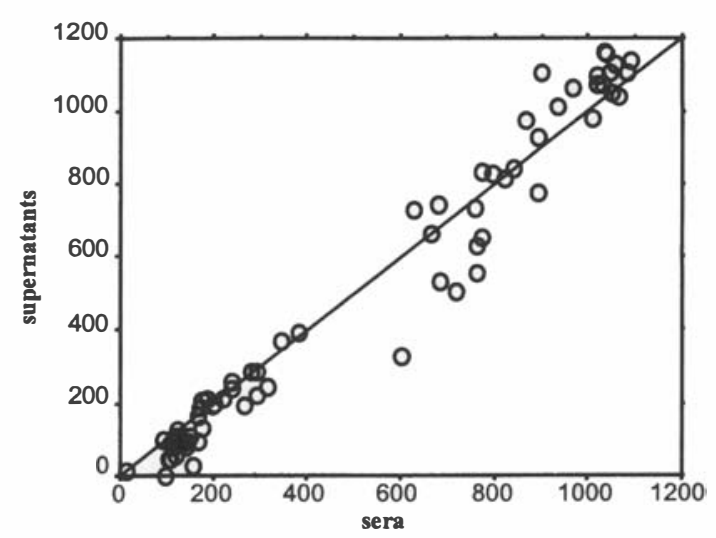

Figure 4. Scattergraphs showing individual paired IgM levels against PGL-I obtained by ELISA $\left(405 \mathrm{~nm} \times 10^{3}\right)$ in whole sera and in polyethylene glycol 600 treated supernatants $(r=0.983, P \leq 0 \cdot 01)$. 
Table 2. Comparison of positive or negative results of anti-PGL-I IgM antibodies isolated from circulating immune complexes in leprosy patients with or without reactions (type 1 or type 2 )

\begin{tabular}{lccc}
\hline & Positive & Negative & Total \\
\hline Without reaction & 9 & 44 & 53 \\
Reaction type 1 or type 2 & 6 & 11 & 17 \\
Total & 15 & 55 & 70 \\
\hline$\chi^{2}=0 \cdot 171, P>0.05$. & & &
\end{tabular}

Serial sera were collected during leprosy reaction, but there was no oscillation of the serology titres (data not shown).

\section{Discussion}

The specific PGL-I antigen from Mycobacterium leprae had been largely used for serological studies in leprosy diagnosis, although it is not used routinely. As shown in this report, almost all multibacillary leprosy patients (LL and BL) have high levels of IgG and IgM against PGL-I. ${ }^{2-4}$ In the present work, leprosy sera for PGL-I serology were tested by ELISA and the results are in agreement with our previous work. ${ }^{14,17}$ High antibody titres were observed in the multibacillary group (LL and BL) compared with low titres in the paucibacillary group (BT and TT) and controls. The specific IgM antibodies against PGL-I had higher titres while IgG presented low titres in the sera and in the PEG 6000 precipitates from CIC. In the present study, almost all the patients studied had not received specific leprosy treatment and, the attention was focused on $\operatorname{IgM}$, as the majority of the studies in leprosy concern this immunoglobulin.

The IgG and IgM antibody against PGL-I isolated from CIC by PEG precipitation test had the same spectral distribution observed in serological studies by ELISA, that extends our previous observation. ${ }^{17}$

The present data comparing the frequency of specific antibody present in the whole serum with that in dissociated CIC, do not confirm our hypothesis since leprosy patients with low antibody levels in serum also have low antibody titres measured by ELISA in CIC. Other factors for the false-negativity in the multibacillary patients must be investigated, such as concomitant acquired immunosuppression. Among the three typical multibacillary leprosy patients, whose serological and CIC analysis were negative, one of them was co-infected with human immunodeficiency virus (HIV). Another explanation for the low antibody levels is that perhaps sero-positivity is related to high systemic and skin bacterial load. Perhaps exclusive high cutaneous bacterial load does not produce high levels of antibodies. We also observed two patients with a negative bacterial index and high positivity for serology, the histopathology and Mitsuda reaction, suggesting the multibacillary form. In these cases, perhaps the systemic bacterial load correlated with the high antibody titres, but not with the skin bacterial load.

The levels of specific free antibodies and isolated antibodies from the CIC were correlated, and the presence of CIC did not modify these antibodies levels as detected by 
ELISA using the glycolipid PGL-I antigen. The CIC precipitation method by PEG does not increase the sensitivity of the ELISA test (Table 1). This is in sharp contrast with the results described by Bhattacharya et al., ${ }^{18}$ studying CIC by PEG precipitation method in tuberculosis. They presented data comparing the frequency of antibody with that of immune complexes. Circulating immune complexes were less frequently observed in their control subjects. However, the data presented by Bhattacharya et al. ${ }^{18}$ did not give any assessment of the antigenic components of Mycobacterium tuberculosis in the immune complexes.

The CIC isolation by the $2.5 \%$ PEG precipitation is very efficient. The supernatant after the first precipitation had similar antibody levels as was found in serology analysis, so PEG used in this condition did not precipitate the free immunoglobulins present in the sera. Submitting this supernatant to another re-precipitation by PEG, very low or no antibody was found in the second precipitate, it demonstrated that all CIC have been effectively detected in the first precipitation. The supernatant resulted after the second precipitation showed almost the same antibody against PGL-I.

Analysing the levels of specific antibodies in sera and in CIC, we did not find any difference between patients with or without reaction (reversal reaction and ENL). Some authors have demonstrated that levels of free specific antibodies were not increased in reactional forms. ${ }^{19,20}$ Separate analysis of different leprosy reactions did not show any difference in patients with reaction type 1 or 2 , comparing to patients without leprosy reaction.

Patients with reaction type 1 presented a spectral results according to leprosy form. Paucilbacillary patients (BT) presented low levels of antibodies in sera and in CIC and; multibacillary patients (BL), high anti-PGL-I titres. These findings show that high levels of specific antibody, free or binding to $\mathrm{CIC}$, is not related to leprosy reaction type 1 , but to leprosy form.

Unfortunately, this study did not include a large number of patients with reaction type 2, as we analysed patients before the introduction of specific treatment. Most patients have ENL during the treatment, and we could not include patients with a long period of treatment, as these patients would have low levels of anti-PGL-I. In our previous work, ${ }^{17}$ we have not found statistically significant difference, comparing patients with and without type 2 reaction, during specific treatment. Some authors reported that there is a decrease of antibodies during ENL and an increase after this reaction. This antibody level variation could be due to residual deposition of antibodies or immune complexes. ${ }^{3,21}$

In this report, we were testing only the specific CIC containing PGL-I antigens and antiPGL-I antibodies. Such specific CIC did not seem to be involved in leprosy reaction. Other antigen or antibody could be involved, since Ramanathan et al. ${ }^{10}$ reported different results. These authors measured CIC by PEG precipitation, and found a high titre of total CIC precipitates in all the patients who presented with a leprosy reaction. They also found that although BT and LL patients had elevated CIC titres, this increase was much less, compared to BT with reaction and ENL, respectively.

A deficiency in any of the complement components could be responsible for the lack of dissolution of immune aggregates in plasma, and thus further precipitate them in various tissues during the inflammatory processes. ${ }^{11,22}$ According to our findings, we can conclude that leprosy patients, mainly BL + LL forms, produce specific CIC and their presence in peripheral circulation are not related to leprosy reactions. However, we are not able to conclude if the peripheral specific CIC reflect part of the immune complexes that are deposited in the tissues and if they have an important immunological role. 


\section{Acknowledgements}

This study was supported by CNPq (Conselho Nacional de Desenvolvimento Científico e Tecnológico), Brazil, which provided a scholarship for the first author; and partially by an ANRS (RIN 102), France.

\section{References}

${ }^{1}$ Brennan PJ, Barrow WW. Evidence for species-specific lipid antigens in Mycobacterium leprae. Int J Lepr Other Mycobact Dis, 1980; 48: 382-387.

2 Cho S-N, Yanagihara DL, Hunter SW, Gelber RH, Brennan PJ. Serological specificity of phenolic glycolipid I from Mycobacterium leprae and use in serodiagnosis of leprosy. Infect Immun, 1983; 41: 1077-1083.

${ }^{3}$ Levis WR, Meeker HC, Schuller-Levis G, Sersen E, Schwerer R. IgM and IgG antibodies to phenolic glycolipid I from Mycobacterium leprae in leprosy: insight into patient monitoring, erythema nodosum leprosum, and bacillary persistence. J Invest Dermatol, 1986; 86: 529-534.

4 Miller RA, Gorder D, Harnisch JP. Antibodies to phenolic glycolipid-I during long term therapy: serial measurements in individual patients. Int J Lepr Other Mycobact Dis, 1987; 55: 633-636.

5 Brostoff J, Lenzini L, Rottoli L. Immune complexes in the spectrum of tuberculosis. Tubercle, 1981; 62: 169-173.

6 Carr RI, Chakrabarty AK, Brunda MJ, Davidson PT, Damle PB, Hardtke MA, Gilbride KJ, Minden P. Immune complexes and antibodies to BCG in sera from patients with mycobacterial infections. Clin Exp Immunol, 1980; 39: 562-569.

7 Grange JM. The humoral immune responses in tuberculosis: its nature, biological role and diagnostic usefulness. Adv Tuberc Res, 1984; 21: 1-78.

8 Simmoney N, Molina JM, Molimard M, Oksenhendler E, Lagrange PH. Circulating immune complexes in human tuberculosis sera: demonstration of specific antibodies against Mycobacterium tuberculosis glycolipid (DAT, PGLTbl, LOS) antigens in isolated circulating immunes complexes. Eur J Clin Invest, 1997; 27: 128-134.

9 Bjorvatn B, Bametson RS, Kronvall G, Zubler RH, Lambert PH. Immune complexes and complement hyperctabolism in patients with leprosy. Clin Exp Immunol, 1976; 26: 388-396.

10 Ramanathan VD, Parkash O, Ramu G, Parker D, Curtis J, Sengupta U, Turk JL. Isolation and analysis of circulating immune complexes in leprosy. Clin Immunol Immunopathol, 1984; 32: 261-268.

11 Sehgal VN, Sharma V, Sharma VK. Comprehensive evaluation of complement components in the course of type I (lepra) and type II (ENL) reactions. Int J Dermatol, 1989; 28: 32-35.

12 Daha MR. Measurement and role of immune complexes in disease. J Int Fed Clin Chem, 1993; 5: $232-236$.

13 Ridley DS, Jopling WH. A classification of leprosy for research purposes. Lepr Rev, 1962; 33: 119-128.

14 Cruaud P, Yamashita JT, Casabona NM, Papa F, David HL. Evaluation of a novel 2,3-diacyl-trehalose-2' -sulphate (SL IV) antigen for case finding and diagnosis of leprosy and tuberculosis. Res Microbiol, 1990; 141: 679-694.

${ }^{15}$ Louzir H, Ternynck T, Gorgi Y, Ayed K, Avrameas S. Enzyme immunoassay analysis of antibody specificities present in the circulating immune complexes of selected pathological sera. J Immunol Methods, 1988; 114: 145153.

16 Ohlson S, Zetterstrand K. Detection of circulating immune complexes by PEG precipitation combined with ELISA. J Immunol Methods, 1985; 77: 87-93.

17 Yamashita JT, Cruaud P, Papa F, Rotta O, David HL. Circulating immune complexes in leprosy sera: demonstration of antibodies against mycobacterial glycolipidic antigens in isolated immune complexes. Int $J$ Lepr Other Mycobact Dis, 1993; 61: 44-50.

18 Bhattacharya A, Ranadive SN, Kale M, Bhattacharya S. Antibody-based enzyme-linked immunosorbent assay for determination of immune complexes in clinical tuberculosis. Am Rev Respir Dis, 1986; 134: 205-209.

19 Schwerer B, Meeker HC, Sersen G, Levis WR. IgM antibodies against phenolic glycolipid I from Mycobacterium leprae in leprosy sera: relationship to bacterial index and erythema nodosum leprosum. Acta Leprol (Geneve), 1984; 2 : 395-402.

${ }^{20}$ Lyons NF, Shannon EJ, Ellis BPB, Naafs B. Association of IgG and IgM antibodies to phenolic glycolipid-I antigen of Mycobacterium leprae with disease parameters in multibacillary leprosy patients. Le pr Rev, 1988; 59: 45-52.

21 Andreoli A, Brett SJ, Draper P, Payne SN, Rook GAW. Changes in circulating antibody levels to the major phenolic glyclipid during erythema nodosum leprosum in leprosy patients. Int J Lepr Other Mycobact Dis, 1985; 53: $211-217$.

22 Chakrabarty AK, Kashyap A, Sehgal VN, Saha K. Solubilization of preformed immune complexes in sera of patients with type 1 and type 2 lepra reactions. Int J Lepr Other Mycobact Dis, 1988; 56: 559-565. 